\title{
AS MARCAS DO INTERPRETE DE LÍNGUA DE SINAIS NA ESCOLA INCLUSIVA
}

\section{Paula Michelle da Silva Pereira}

\section{RESUMO}

Este trabalho tem como objetivo discutir algumas das conseqüências da atuação de um intérprete de língua de sinais na sala de aula sem que este tenha tido minimamente uma formação superior ou preparo para ali atuar. No decorrer da pesquisa ficou evidenciado que o intérprete de língua de sinais é um profissional que intervém nas relações do aluno surdo - tanto com os colegas, quanto com os professores e também com a família. O intérprete de língua de sinais não é neutro.

\author{
PALAVRAS-CHAVE
}

Intérprete de língua de sinais; Formação; Surdez.

\section{THE MARKS OF THE SIGN LANGUAGE INTERPRETER IN THE INCLUSIVE SCHOOL}

\section{ABSTRACT}

This paper aims to discuss some of the consequences of the presence of a sign language interpreter in the classroom, when he or she has not had higher education or been formally prepared to work in that environment. In the course of the research it became clear that the sign language interpreter is a professional who intervenes in the deaf students' school relations, that is, their relations with classmates, teachers, and family. The sign language interpreter is not neutral.

\section{KEY WORDS}

Sign language interpreter; Education; Deafness. 


\title{
ARTIGO \\ Processos Tradutórios, Línguas de Sinais e Educação \\ Grupo de Estudos e Subjetividade
}

\section{INTRODUÇÃO:}

Este trabalho discute as conseqüências que a falta de formação do intérprete de língua de sinais - ILS — que atua na educação pode causar para o aluno surdo. Minha análise restringir-se-á à área educacional, pois é exerço a função de ILS.

Meu objetivo não é oferecer todas as possíveis respostas, mas sim refletir sobre a importância da formação do ILS, com o intuito de contribuir para uma posterior elaboração curricular no curso de Pedagogia, visando futuros educadores que desejem atuar como ILS no Ensino Fundamental.

Faz-se necessário iniciar esta discussão descrevendo a concepção de interpretação adotada neste estudo. A palavra "traduzir”, segundo Martins (2003), significa, do ponto de vista diacrônico, “fazer passar de um lugar para o outro”. Isto é, produzir significados, na língua traduzida, a partir do texto produzido inicialmente na língua estrangeira.

No caso do ILS, significa:

\begin{abstract}
O intérprete de língua de sinais está entre a comunidade ouvinte e a comunidade surda, proporcionando um (des) entendimento entre esses dois grupos lingüísticos. E, ao realizar o seu trabalho, é essencial que ele converta para a língua de sinais a mensagem dita em português, buscando a "fidelidade", concebida neste trabalho como equivalência de mensagens. O ILS produzirá um outro/mesmo discurso: outro porque o fato de buscar um sinal/palavra equivalente já é um movimento diferente; e mesmo, pelo fato do discurso ser correspondente ao discurso do português. (ROSA, 2005, p. 83).
\end{abstract}

O estudo deste caso refere-se a um aluno surdo do sexo masculino, com 15 anos, que tenho acompanhado há um ano e meio e atualmente está na $8^{a}$ série. Neste estudo, ele será identificado pela inicial de seu primeiro nome: P.

P. tem surdez profunda, sua mãe é fonoaudióloga e o pai administrador de empresas; a formação acadêmica da mãe foi determinante para a escolha da abordagem educacional escolhida para seu filho: a proposta bilíngüe, ou seja, a língua de sinais como L1 e o português como L2.

Segundo relato da mãe, quando P. tinha por volta de cinco anos foi estudada a possibilidade de fazer o implante coclear; contudo, em razão de alguns imprevistos não foi possível tal intervenção. Essa negativa levou a mãe de P. a estudar as diversas abordagens sobre a surdez e conseqüentemente a educação de surdos. Como resultado das informações obtidas, fez a opção por ser o conhecimento escolar mediado pela língua de sinais, servindose do profissional ILS. 
Os dois primeiros anos escolares foram cursados em uma escola especial para surdos. Insatisfeita com esse ensino, ela optou por procurar uma escola regular e contratou um ILS, que tem sido presente desde a $2^{\mathrm{a}}$ série do Ensino Fundamental.

Vale ressaltar que o convívio da criança surda com a língua de sinais desde primeira infância é escolha dos pais.

\title{
1 A BUSCA PELO PROFISSIONAL INTÉRPRETE DE LÍNGUA DE SINAIS
}

Durante seu processo escolar, P. teve cinco intérpretes diferentes, cujas formações escolares variavam: Ensino Médio completo (1), Nível Superior completo (2) e incompleto (2). Das cinco intérpretes, somente uma não aprendeu a língua de sinais na igreja.

Segundo Rosa:

\begin{abstract}
A história dos intérpretes apresenta dois locais de formação: a igreja ou lugares públicos freqüentados por surdos. Isto é, a aprendizagem da língua de sinais se dá no contato direto com as pessoas surdas e ser reconhecido como intérprete depende da legitimação desse papel por um grupo de surdos. (ROSA, 2005, p.114).
\end{abstract}

No momento em que fui entrevistada pela mãe de P., ela declarou que, naquele momento, não importava se eu era ou não fluente na língua de sinais, pois, diante dos problemas enfrentados anteriormente com a intérprete sem formação superior, preferia uma ILS com formação superior ou em formação.

É possível perceber que a primeira marca deixada por uma ILS sem formação é a diminuição da língua de sinais e, por essa razão, a língua tornou-se secundária no processo tradutório e a formação tornou-se ponto crucial para a escolha da ILS que trabalharia com P.

Durante o processo seletivo, o maior interesse da mãe era com relação a minha formação acadêmica; no momento da entrevista, eu cursava o $2^{\circ}$ ano de Pedagogia em Educação Especial na PUC. Minha fluência na língua de sinais era irrelevante, sendo dado maior destaque a minha experiência empírica no trabalho com pessoas surdas.

Segundo a mãe de P. o intérprete além de gostar muito do que faz, precisa também ter formação. Porque como em todo trabalho é necessário ser muito profissional, ter técnica e respeitar profundamente a ética. Em especial no trabalho com crianças, durante o ensino fundamental, onde a interpretação não é "crua e literal", mas exige o conhecimento dos conteúdos, bem como, domínio de didáticas especiais, para (re)explicar de outra forma, tendo 
sempre uma percepção muito clara, se houve ou não compreensão e alcance por parte do aluno.

Diante dos relatos das minhas experiências e em razão da indicação da pedagoga do Centro de Pesquisa e Reabilitação e Estudos Prof. Dr. Gabriel Porto - CEPRE/ FCM /UNICAMP — com quem obtidas, faço estágio há cerca de dois anos, a partir desta entrevista fui aceita como intérprete para P.

Neste aspecto é notória a marca deixada pela intérprete anterior, ou seja, a língua de sinais deixou de ser prioridade para a atuação do ILS na educação, dando espaço para a formação acadêmica. Sendo o intérprete o profissional que está entre duas línguas, como pode a fluência da língua ser desconsiderada? A questão é que não pode: a fluência e o conhecimento das línguas envolvidas são necessários ao ILS.

Para realizar essa tarefa, é necessário ao intérprete de língua de sinais conhecer os
equivalentes entre as expressões típicas da língua de partida (português) e as da
língua de chegada (língua de sinais), nem sempre vertendo em sinais todas as
palavras pronunciadas pelo ouvinte, mas procurando manter o sentido e buscando os
efeitos produzidos pelo pronunciador do enunciado oral. (ROSA, 2005, p.92).

\section{AS MARCAS NA ESCOLA}

No meu primeiro dia de trabalho, a orientadora responsável pelo Ensino Fundamental apresentou-me à professora que estava na sala como a nova intérprete de P. Fui muito bem recebida tanto pela professora como pelos demais alunos. Na aula seguinte, a professora de português iria aplicar uma prova que já estava previamente agendada com a classe. Como de costume, ela entregou as provas e determinou o tempo para a sua resolução; quando vi o conteúdo da prova (verbos, preposições, etc.) e a dificuldade que o aluno surdo estava tendo para responder as questões, perguntei para a professora — que estava sentada ao meu lado — como seria sua forma de avaliação, visto que P. não utilizava essas ferramentas da gramática da língua portuguesa em sua escrita.

Por meio dessa situação, descobri que a professora estava há pouco tempo na escola, e não sabia como avaliar nem como transmitir o conhecimento necessário para o aluno surdo. Combinamos uma conversa para ela inteirar-se sobre a surdez, língua de sinais e tudo mais que se refere à vida de uma pessoa surda — esclarecimentos que ela, até aquele momento, não havia recebido da escola, embora o aluno, então já no segundo semestre da $6^{a}$ série, ali estivesse desde a $4^{\mathrm{a}}$ série. 
No decorrer dos dias e com a realização das provas agendadas, P. ficava cada vez mais agressivo em suas atitudes com os colegas e em vários momentos não prestava atenção na explicação dos professores; quando eu tentava chamar sua atenção, ele se esquivava e se virava para não ver o que era interpretado. Em um desses momentos, a professora de matemática me relatou que ela tinha muita dificuldade com a ILS anterior, pois, segundo a professora, a intérprete apresentava dificuldades em compreender o conteúdo de matemática e transmitia esta insegurança para o aluno. Em determinados momentos, os dois discutiam e chegavam ao ponto de se agredirem; outras vezes, a ILS dirigia-se à orientadora educacional da escola para reclamar da postura de P., ou vice-versa: este ia reclamar da ILS.

Segundo Theodor (1976, p13), "tradutor é aquele que torna compreensível aquilo que antes era ininteligível, e já por isso deve ser encarado como um intérprete por excelência”. Em seu livro, Theodor (1976) procura demonstrar a importância de uma interpretação correta do tradutor do texto original, para que, depois de realizada sua tarefa, o texto seja de possível compreensão para os leitores da língua para a qual foi traduzido (ROSA 2005, p. 57 e 58).

O mesmo ocorre com o ILS: não compreendendo o conteúdo exposto pelo professor, ele fica impossibilitado de realizar o ato interpretativo. Com esses acontecimentos, a ILS em questão, além de entrar em atrito com o aluno freqüentemente, começou a faltar e a não se justificar. Sabemos que, para esse aluno, a falta da ILS é como se ele mesmo tivesse faltado, pois o português oral lhe é inacessível.

Os desentendimentos anteriores com a outra ILS proporcionaram marcas de insegurança no aluno e desconfiança com relação ao meu trabalho e, principalmente, à minha freqüência na escola. Esta situação perdurou até o final do ano letivo de 2004.

O ano letivo de 2005 teve início em 31 de janeiro. Uma semana antes, a mãe do aluno surdo telefonou-me para saber se continuaria a ser ILS do seu filho; diante da minha confirmação, ela informou-me a data de início das aulas.

No primeiro dia de aula ela relatou que na noite anterior, antes de dormir, P. indagou se eu estaria mesmo na aula.

Sua insegurança é notória até hoje: quando eu preciso faltar e aviso com antecedência, percebo sua insatisfação; mesmo que ele não produza nada no dia em que estou presente, a minha presença representa a ponte entre o conhecimento e a sua aprendizagem na sala de aula. Sem a presença do ILS, o aluno surdo fica sem acesso ao conteúdo escolar exposto pelo professor. 
Podemos confirmar isso no relato feito pela professora após um determinado dia em que, tendo avisado com antecedência, foi necessário ausentar-me: “A professora de português veio relatar a produção do P. e disse: ‘Quando você não está ele não faz nada, só bate-papo’ ’”.

Por meio dessa fala, observei que não só P. depende do ILS: os professores também são inseguros e não sabem como lidar com o aluno surdo na ausência do ILS. Assim sendo, nem sempre a não-formação ocorre somente no ILS, mas revela-se, também, na atuação do professor responsável pela sala e/ou disciplina.

A presença do ILS em sala de aula foi proposta para que pudesse minimizar os problemas lingüísticos e de interação social, já que o professor e o aluno surdo usam línguas diferentes para comunicar-se. Com isso, a ILS faz o papel de mediadora dos conhecimentos, informações e relatos que a professora e outros alunos possam trazer ao cotidiano da sala.

O professor titular trabalha com a sala como se todos os alunos fossem "pares iguais”. Sabemos que cada aluno tem suas particularidades; contudo, em relação ao aluno surdo, o professor precisa usar ferramentas para despertar o seu interesse para o conteúdo das diferentes áreas do conhecimento, visto que o ILS não tem a mesma formação específica que o professor da classe.

Outro ponto importante é a posição, tanto do aluno como do intérprete, na sala de aula: P. tem seu lugar fixo, senta-se na primeira carteira, diante da mesa, ao lado da porta; a ILS senta-se a sua frente - localização estratégica, pois tanto P. como os professores têm uma ótima visão um do outro e da lousa, que é o instrumento utilizado pelos professores para a explicação dos conteúdos pertinentes a cada disciplina. Além disso, essa disposição facilita também a intervenção e o acompanhamento dos professores. "O ato de interpretar corresponde ao processo cognitivo pelo qual se trocam mensagens de uma língua a outra, sejam elas orais ou sinalizadas” (LACERDA, 2000, p.60).

É também constante a comparação que o P. faz entre o meu trabalho e os das intérpretes anteriores. Durante todo o período em que estive trabalhando com este aluno, por diversas vezes ele comparou a minha postura como ILS com as demais profissionais que já atuaram com ele; em alguns momentos, para tirar proveito de algumas situações; em outros, para criticar as ILS anteriores, provavelmente devido aos problemas ocorridos no ano de 2004, entre eles a postura: pareciam não saber separar a amizade com o sujeito surdo da sua atuação como intérprete de língua de sinais. 
O aluno precisa saber distinguir o papel da intérprete de língua de sinais na escola; em contrapartida, a profissional deve deixar claro qual será seu tipo de relacionamento com o aluno: seja a atitude paternalista, seja a neutralidade profissional, as duas propostas precisam estar bem definidas para o surdo, pois é ele quem irá utilizar seus serviços.

Ainda falando sobre as marcas, especificamente para P. ficaram lacunas - adquiridas pela constante ausência do ILS ao local de trabalho - no processo de aprendizagem, em diversos conteúdos aplicados no ano de 2004 e que são base para o estudo da sétima série.

Essas dificuldades estão sendo aos poucos sanadas com encontros regulares entre mim e a mãe do aluno surdo: discutimos qual a melhor forma para que ele absorva o conhecimento exposto na escola, considerando suas limitações e possibilidades. A mãe trabalha essas dificuldades em casa durante a elaboração dos deveres e no período de estudo para as provas.

Em outros momentos, reúno-me com a orientadora pedagógica do Ensino Fundamental, para saber como está sendo o desempenho de P. neste ano letivo, visto que ela o tem acompanhado desde a quinta série e esteve presente durante todo o processo, tanto de adaptação de novos intérpretes, como das dificuldades apresentadas pela ILS anterior.

Tenho enfrentado alguns problemas de comportamento por parte de P., por dois motivos: o primeiro é que ele, assim como qualquer outro aluno da sala, é um adolescente, que tem sua própria personalidade; o segundo é a péssima experiência que ele teve com a outra intérprete, o que lhe trouxe insegurança e o levou a resguardar-se de uma aproximação comigo. Meu desafio não tem sido apenas interpretar, mas também restaurar a credibilidade de P. com relação ao profissional intérprete de língua de sinais.

Vale ressaltar que é necessário ao surdo saber utilizar os serviços da intérprete, porém esta não é uma tarefa fácil para ele, já que esta atividade é realizada de forma individual, levando muitas vezes o aluno surdo a confundir prestação de serviço com disponibilidade irrestrita.

O papel do ILS é mediar o conteúdo que está sendo aplicado em sala pelos professores ao aluno surdo, porém por diversas vezes esse papel não é claro para o intérprete nem para o aluno; tampouco o é para o professor titular.

O ILS deve procurar levar a mensagem da forma mais clara e objetiva para o aluno surdo, em determinados momentos aprofundando mais em alguns detalhes do que em outros, para que o aluno possa realmente absorver tal conhecimento. Em uma interpretação literal, isso não ocorre, pois o ILS somente transmite o que o professor fala, sem considerar se está 
sendo significativo para o aluno ou não. É relevante que o intérprete saiba mediar e entender o olhar do aluno, descobrir se ele percebe, se está entendendo ou não o conteúdo interpretado/ensinado:

Muitas vezes a fim de esclarecer uma ponte entre as duas culturas a tradução tem que explicitar conhecimentos que são comuns entre os leitores do original, mas dos quais não partilham os leitores da tradução, por meio de notas de rodapé glossários, e outros recursos (TRAVAGLIZ, 2003, p. 85).

Isso não significa que o ILS deva esclarecer todas as dúvidas do aluno, mas sim verificar suas dificuldades e levá-las ao professor para que ele possa intervir de maneira eficaz, sanando assim todas as dúvidas do educando.

Em diversos momentos de minha atuação em sala de aula, P. manifestava algumas dúvidas sobre o conteúdo que o professor estava explicando para a sala e, quando eu o orientava a perguntar ao professor, ele se negava e pedia para que eu mesma explicasse para ele. Em outros momentos, principalmente relacionados ao conteúdo de matemática, que exige o raciocínio lógico e no qual P. apresenta maior dificuldade, notei que, quando a sala como um todo apresentava dificuldades, a professora aproximava-se do aluno surdo para verificar suas dúvidas; contudo, no cotidiano, quando a classe não revelava dificuldades, esta intervenção não acontecia.

\section{CONSIDERAÇÕES FINAIS:}

Problemas - para a relação tanto professor-aluno como intérprete-aluno — podem ser causados pela falta de formação do intérprete, pois, por atuar como mediador entre as partes, é necessário e indispensável que saiba a função da escola na vida de cada aluno e principalmente do aluno surdo.

Para que a atuação do intérprete de língua de sinais seja realmente significativa, tanto para o aluno e sua família como para os demais profissionais da educação envolvidos, é necessário que, além de uma formação adequada e específica, ele tenha também consciência de como sua presença dentro da sala de aula e sua convivência diária com o aluno surdo influenciam suas atitudes e ações dentro e fora da escola.

Isso porque os alunos, principalmente do Ensino Fundamental e Médio, estão construindo seu caráter, passam a maior parte de seu dia dentro da escola na companhia de 
professores, orientadores, monitores e demais profissionais e seu referencial, nesse período, são os profissionais que o rodeiam.

Em especial, no caso do aluno surdo, sua referência lingüística dentro da escola é o intérprete de língua de sinais, pois — diferentemente da sua relação com professores e colegas ouvintes, que não compreendem a língua de sinais - é com ele que o aluno tem contato direto, por utilizarem uma língua em comum.

Acredito que, se os intérpretes de língua de sinais que atuam na educação tiverem uma formação adequada, que inclua o aspecto lingüístico e o pedagógico, poderão compreender importância do seu papel na escola inclusiva.

Provavelmente problemas como os enfrentados por P. serão diminuídos e os alunos surdos que tiverem acesso a esta abordagem educacional terão um ensino significativo, e saberão valorizar o profissional intérprete de língua de sinais.

\section{REFERÊNCIAS:}

BRASIL, Secretaria de Educação Especial. Língua Brasileira de Sinais. (Org.) Lucinda F. Brito et. al. Brasília: SEEP. 1997.

LACERDA, C. B. F. de; GÓES, M. C. R. (Org). SURDEZ: ${ }^{1}$ processos educativos e subjetividade. São Paulo: LOVISE, 2000.

MARTINS, R. T. Tradução automática: um conflito paradigmático. Disponível em <http://www.nilc.icmc.usp.br/til2003/oral/RonaldoMartins_31.pdf.>. Acesso em: 28 de fevereiro de 2004.

SOUZA, R. M. de. Que palavra que te falta? São Paulo, 1998.

ROSA, Andréa da Silva. Entre a visibilidade da tradução da língua de sinais e a invisibilidade da tarefa do intérprete. Dissertação (Mestrado em Educação) Universidade Estadual de Campinas, 2005.

TRAVAGLIA, N. G. Tradução retextualização: a tradução numa perspectiva textual. Uberlândia: UDUFU, 2003.

THEODOR, E. Tradução: oficio e arte. 3. ed. São Paulo: Cultrix.

\footnotetext{
${ }^{1}$ A ABNT não recomenda negrito para o registro do subtítulo.
} 
